\title{
SEASONAL CRUSTAL DEFORMATIONS AROUND THE EASTERN TIBETAN PLATEAU CONSTRAINED BY GPS, GRACE AND HYDROLOGICAL MODEL
}

\author{
Yunfei XIANG ${ }^{1)}$ *, Jianping YUE ${ }^{1)}$, Yankai BIAN ${ }^{1)}$, Dongjian CAI ${ }^{2)}$ and Kanglin CONG ${ }^{1)}$ \\ ${ }^{1)}$ School of Earth Sciences and Engineering, Hohai University, Nanjing 211100, China \\ ${ }^{2)}$ Suzhou Industrial Park Surveying, Mapping and Geoinformation Co., Ltd., Suzhou 215027, China
}

*Corresponding author's e-mail: m18262635915@163.com

\begin{tabular}{l} 
ARTICLE INFO \\
\hline Article history: \\
Received 6 June 2019 \\
Accepted 19 September 2019 \\
Available online 31 Octiber 2019
\end{tabular}

\section{Keywords:}

LSDM

GRACE

Hydrological loading deformations MCSSA

XWT

Eastern Tibetan Plateau

\begin{abstract}
In order to characterize the seasonal crustal deformations induced by hydrological loading around the eastern Tibetan Plateau, the data sets of Global Positioning System (GPS), Land Surface Discharge Model (LSDM), and Gravity Recovery and Climate Experiment (GRACE) at 24 sites situated in this region are collected. The hydrological loading effects around the eastern Tibetan Plateau exhibit strong latitude dependence. The Root Mean Square (RMS) values tend to occurrence a downward trend as the latitude increases, and large RMS values are cumulated at the sites located in the low-latitude area of this region. Meanwhile, the amplitude of the annual signals of three data sets modeled by Monte Carlo Singular Spectrum Analysis (MCSSA) in lowlatitude area is larger than mid- and high-latitude area. Then, Cross Wavelet Transform (XWT) is adopted to assess the consistency between different data sets. The XWT-based semblance of GPS/GRACE above 0.9 are observed at $67 \%$ of the sites, while it reaches $79 \%$ for GPS/LSDM, implying LSDM can well model the hydrological loading deformations around the eastern Tibetan Plateau in comparison with GRACE. We also evaluate the effects of hydrological loading on GPS observations from the variations of RMS values, noise properties, and velocity uncertainties. After applying hydrological loading correction, the reduction of RMS values and velocity uncertainties appears at most sites. Moreover, the magnitude of Flicker Noise (FN) in most GPS observations is decreased, whereas the magnitude of White Noise (WN) is increased accordingly. The results suggest that applying hydrological loading correction can reduce the magnitude of FN in most GPS observations, and improve the precision of velocity estimation.
\end{abstract}

\section{INTRODUCTION}

The Tibetan Plateau is the highest altitude plateau in the world, which is located at the junction of the Eurasian plate and the Indian plate. Due to the collision between India plate and Eurasian plate, the Tibetan Plateau has been moving towards the northeast. Meanwhile, several major earthquakes (e.g., $2015 \mathrm{Mw} 7.8$ Nepal earthquake) occurred in this region due to the collision of two plates ( $\mathrm{Su}$ et al., 2015; Fan et al., 2015; Yagi et al., 2015). The Tibetan Plateau has complicated tectonic movements, which has attracted the interest of many scholars. However, the redistribution of surface mass (i.e., atmospheric, non-tidal oceanic, and hydrological loading) can also result in the long-term crustal deformations, which must be removed before the tectonic movements can be assessed (Bevis et al., 2005; Fritsche et al., 2012; Chanard et al., 2014; Ray et al., 2013). The effects of mass loading should be understood thoroughly in order to distinguish non-tectonic signals, and it can help to evaluate the crustal evolution of this region. Among these loads, the crustal deformations induced by hydrological loading is relatively large compared with atmospheric and non-tidal oceanic loading, but this load is not well understood due to the fact that the hydrological loading effects are related to the variations of local climate and water storage in different regions (King et al., 2006; van Dam et al., 2007; Liu et al., 2014). In addition, the eastern Tibetan Plateau spans most of Qinghai and Tibet provinces, and parts of Yunnan and Sichuan provinces. Thus, the hydrological loading effects in this region are relatively complicated, which is worth exploring. These factors mentioned above motivate us to characterize the crustal deformations induced by hydrological loading around the eastern Tibetan Plateau using the different kinds of geodetic measurements.

The seasonal crustal deformations induced by the hydrological loading can be captured by Global Positioning System (GPS), modeled by Gravity Recovery and Climate Experiment (GRACE) and hydrological model. Recently, a large number of studies pay attention on characterizing the effects of mass loading at the global and regional by the combined use of GPS, GRACE, and surface loading models (He et al., 2017; Zhang et al., 2018; Pan et al., 2019). van Dam et al. (2007) compared vertical GPS 
residuals with the crustal deformations estimated from GRACE for the sites situated in Europe, and found that the annual signals derived from GPS and GRACE do not agree in amplitude or phase at most sites. Nahmani et al. (2012) explored the hydrological loading deformations associated with the West African Monsoon through the comparison of GPS, GRACE, and loading models. Fu et al. (2012) characterized the seasonal and long-term vertical deformation in the Nepal Himalaya based on GPS and GRACE measurements, and indicated that the good seasonal correlation between GPS and GRACE is due to the improved GPS processing strategies and also because of the strong seasonal hydrological variations in Nepal. Moreira et al. (2016) made a comparison between the geodetic measurements derived from GPS, GRACE, and hydrological model, and confirmed that the GRACE solutions produce the better agreement with GPS time series. Zou et al. (2016) focused on the seasonal variation in the horizontal and vertical movements of southern Tibet by performing a joint analysis of GPS and GRACE data, and found that GPS-derived and GRACEderived seasonal oscillations are in good agreements. $\mathrm{Wu}$ et al. (2017) investigated the seasonal crustal movements in Tianshan area using GPS, GRACE, and Surface Loading Models (SLMs), and confirmed that the consistency between the GPS and SLMs data was higher, which is probably due to the dominant atmospheric loading effects in this region. Li et al. (2019) investigated the surface seasonal mass changes and vertical crustal deformation in North China using the measurements of GPS and GRACE. We also utilized the data sets of GPS and hydrological model to characterize the hydrological loading effects over the mainland China in our previous work (Xiang et al., 2018). On the basis of our previous work, we try to characterize the hydrological loading effects over the eastern Tibetan Plateau using the data sets of GPS, GRACE, and hydrological model, and evaluate the consistency between different data sets in this study. In addition, GPS observations are susceptible to other geophysical effects, local effects, and systematic errors, and the hydrological loading may be not the complete factor of seasonal oscillations in GPS observations after atmospheric and non-tidal oceanic loading correction. Thus, on the other hand, we also discuss the effects of hydrological loading on GPS observations from the variations of Root Mean Square (RMS) values, noise properties, and velocity uncertainties, which may be of help to understand the effects of hydrological loading, and then reveal tectonic movements around the eastern Tibetan Plateau using GPS observations.

\section{DATA SETS AND METHODS}

\subsection{GPS DATA}

In this study, the daily vertical position time series of 24 GPS sites situated in the eastern Tibetan
Plateau, spanning from 2011 to 2016, are utilized, and the spatial distribution of these sites depicted as Figure1. The 24 GPS sites are derived from the Crustal Movement Observation Network of China (CMONOC), which is used for monitoring the crustal movements in the mainland China. The GPS data of 24 sites is processed by GAMIT/GLOBK (version 10.40 ), and more information about the GPS dataprocessing can refer to ftp://ftp.cgps.ac.cn/doc/processing manual.pdf. In the GPS data-processing, the polar tides, ocean tidal loading, and solid-earth tides have been corrected. However, no attention has been paid to the effects of mass loading (i.e., atmospheric, non-tidal oceanic, and hydrological loading) (Xu et al., 2016). For the missing data in the GPS position time series, the piecewise cubic Hermite interpolation is adopted to conduct the gap-filling. Meanwhile, the outliers in the GPS position time series are identified and removed according to the Inter-Quartile Range (IQR) rule (Li et al., 2017a; Li et al., 2017b). In order to better characterize the seasonal variations induced by hydrological loading, Least Squares Fitting (LSF) is utilized to remove the linear trend in the GPS position time series. All of the daily vertical position time series of 24 GPS sites used in this study is available at ftp://ftp.cgps.ac.cn/products/position/, and we utilize the raw solution provided by China Earthquake Administration (CEA).

\subsection{GRACE DATA}

The seasonal crustal deformations induced by hydrological loading can be modeled using GRACE data. The time-varying gravity model adopted in this study is GRACE products Level-2 Release 05 (RL5), which is provided by the University Texas Center for Space Research (CSR). The C20 terms are replaced with the results observed by Satellite Laser Ranging (SLR), and the degree-1 Stokes coefficients are added according to the method of Swenson et al. (2008). Then, the long-term mean gravity field model is subtracted from the data products, and the method given by Kusche et al. (2007) is adopted to filter the residual spherical harmonic coefficients. Since the aim of this study is to determine the vertical crustal deformations caused by hydrological loading, the GRACE Atmosphere and Ocean De-aliasing Level1B (AOD1B) products are not added to the GRACE spherical harmonic solutions. According to the spherical harmonics coefficients and the load Love numbers, the vertical crustal deformations induced by hydrological loading can be computed (Farrell, 1972; van Dam et al., 2007). The calculation formula is as follows:

$$
\begin{aligned}
& \Delta h(\theta, \gamma)= \\
& =R \sum_{l=1}^{\infty} \sum_{m=1}^{l} \bar{P}_{l m}(\cos \theta) \frac{h_{l}}{1+k_{l}}\left(\Delta C_{l m} \cos m y+\Delta S_{l m} \sin m y\right)
\end{aligned}
$$




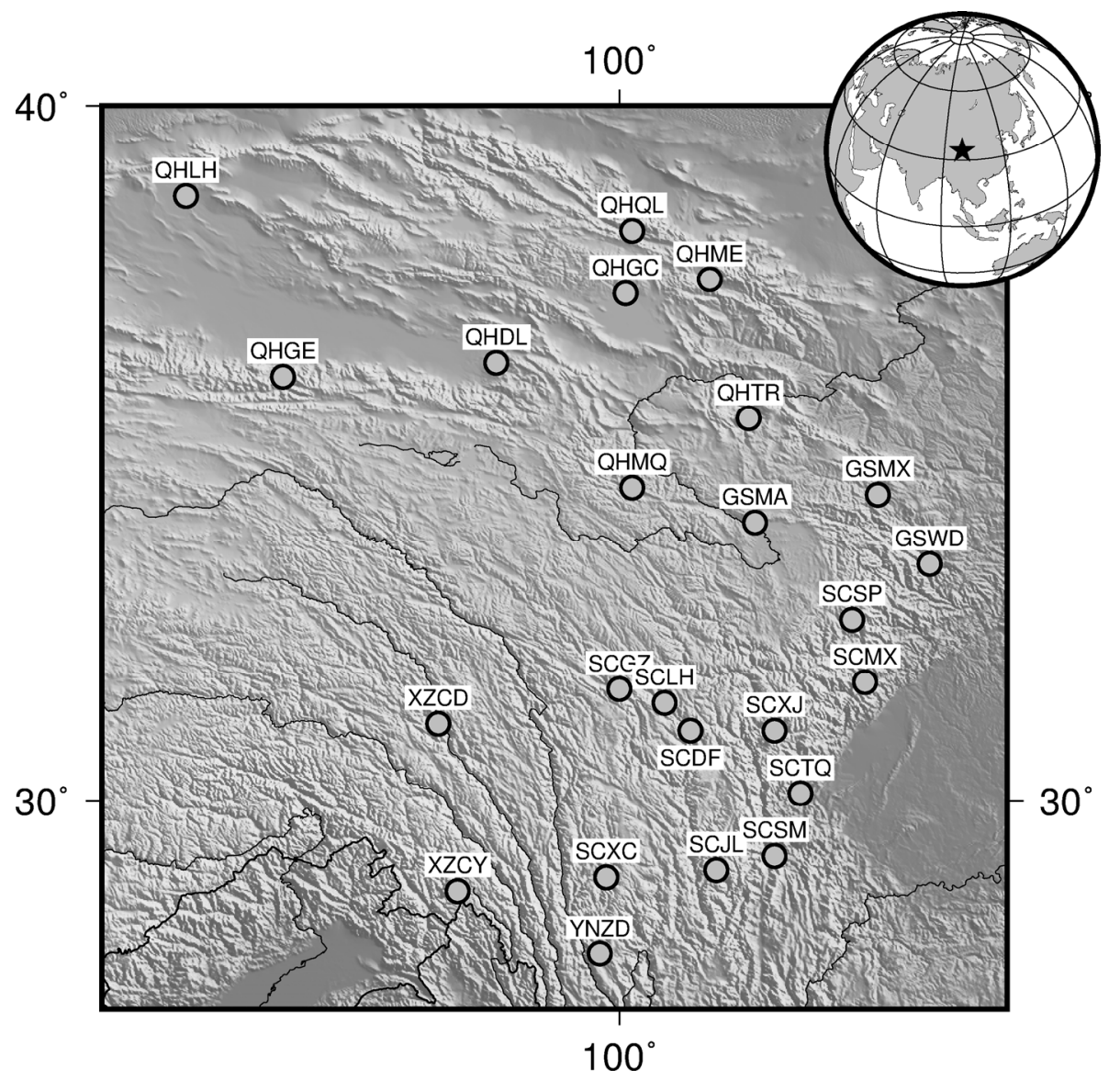

Fig. 1 Spatial distribution of the 24 GPS sites. Gray circles denote the GPS sites.

Where $\Delta h(\theta, \gamma)$ is the crustal deformations in the radial direction; $R$ is the average radius of the Earth; $\bar{P}_{l m}$ are normalized Legendre functions of degree $l$ and order $m ; \Delta C_{l m}$ and $\Delta S_{l m}$ are the residual spherical harmonic coefficients of gravity field; $h_{l}$ and $k_{l}$ are the load Love numbers at the degree $l$.

\subsection{HYDROLOGICAL LOADING MODEL DATA}

The hydrological loading deformations can also be estimated by the hydrological model. In this study, the global Land Surface Discharge Model (LSDM) is utilized to estimate the hydrological loading deformations at each GPS site. LSDM continental water storage considers snow accumulation, soil moisture, and water flow in rivers and lakes given as daily states on a $0.5^{\circ}$ regular global grid. Considering the heterogeneous distribution of terrestrial water storage, the loading deformations is convolved to produce the vertical crustal deformations in the Centre-of-Figure (CF) reference frames based on Green's function theory instead of using the load Love numbers. Dill and Dobslaw (2013) proposed a patched Green's function method to efficiently reduce the needed computer time for the calculation of highresolution loading contributions on a sufficiently dense regular grid. The hydrological loading deformations estimated by LSDM are provided by
German GeoForschungs Zentrum (GFZ), which are available at https://www.gfz-potsdam.de/en/esmdata/. The temporal and spatial resolutions provided grid data are $24 \mathrm{~h}$ and $0.25^{\circ}$. The corresponding hydrological loading deformations at each GPS site are computed based on a bicubic interpolation from the grids. In addition, the deformations induced by atmospheric and non-tidal oceanic loading have been removed from GPS position time series using the grid data provided by GFZ for the better comparison with GRACE measurements.

\subsection{MONTE CARLO SINGULAR SPECTRUM ANALYSIS}

For characterizing the seasonal crustal deformations, it is an important issue to model timevarying seasonal signals accurately. Chen et al. (2013) utilized Singular Spectrum Analysis (SSA) to extract seasonal signals from GPS time series and confirmed that SSA is an effective tool for modeling seasonal signals in comparison with LSF and Kalman filtering. Whereas, colored noise in GPS observations may have similar temporal behavior as annual signal, and therefore can be mistaken as annual signal. Thus, it is necessary to apply the Monte Carlo SSA (MCSSA) to distinguish the annual signal from the colored noise existed in GPS observations. More detail information about the methodology can refer to Allen and Smith (1996). The main idea of MCSSA is to compare whether the partial variance of data and the surrogate 

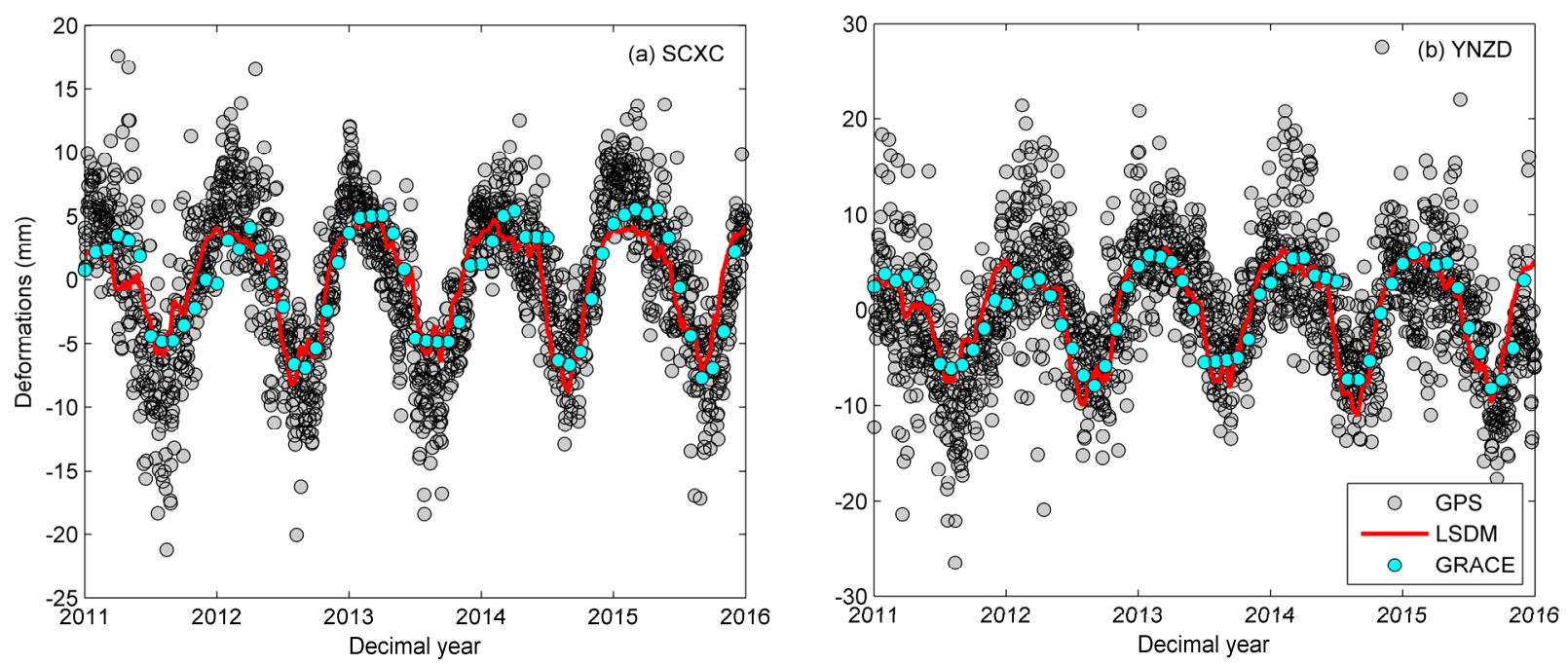

Fig. 2 Comparison of three data sets derived from GPS, LSDM, and GRACE at GPS sites (a) SCXC and (b) YNZD.

data are statistically different. Surrogate data can be constructed according to particular stochastic models. In general, the noise in GPS observations can be described as power law noise. Therefore, the power noise model is utilized to generate surrogate data. Based on the statistical distribution of diagonal elements and the Monte Carlo's confidence interval, we can confirm that the reconstructed signals with the eigenvalues lied outside the confidence interval have geophysical significance.

\subsection{CROSS WAVELET TRANSFORM}

Cross Wavelet Transform (XWT) is the combination of continuous wavelet analysis and cross spectrum, which can expose common power regions and phase relationship between two time series in the time-frequency space (Grinsted et al., 2004). The XWT of two time series $X_{n}$ and $Y_{n}$ is defined as:

$W^{X Y}=W^{X} W^{Y *}$

where the $Y^{*}$ refers to the complex conjugation of $W^{Y}$. The circular mean of the phase is used to measure the phase relationship between two time series. The circular mean of a set of angles $\left(a_{i}, i=1\right.$, $2 \ldots n)$ is calculated by:

$a_{m}=\arg (X, Y)=\arg \left(\frac{1}{n} \sum_{i=1}^{n} \cos \left(\alpha_{i}\right), \frac{1}{n} \sum_{i=1}^{n} \sin \left(\alpha_{i}\right)\right)$

and the circular standard deviation $s=\sqrt{-2 \operatorname{In}(R / n)}$ ( $R=\sqrt{X^{2}+Y^{2}}$ ) is utilized to measure the scatter of angles around the average. Based on $a_{m}$, the XWTbased semblance is computed with the aim of revealing the correlation of two time series intuitively. The mean XWT-based semblance is defined as:

$\rho=\cos \left(\alpha_{m}\right)$

where the value of $\rho$ varies from - 1 (inversely correlated) through 0 (uncorrelated) to 1 (correlated).

\section{RESULTS AND DISCUSSION \\ 3.1. COMPARISON OF DEFORMATIONS DERIVED FROM THREE TECHNIQUES}

After removing the effects of atmospheric and non-tidal ocean loading, the GPS observations of each site are compared with corresponding hydrological loading deformations estimated by LSDM and GRACE. Almost all displacement time series derived from three techniques have pronounced seasonal variations, which are mainly expressed as annual and semi-annual oscillations. Among the three data sets, the range of RMS values of GPS observations is 2.84$8.20 \mathrm{~cm}$ with average value of $5.32 \mathrm{~cm}$, while the range of RMS values of GRACE and LSDM measurements is $1.13-4.78$ and $1.22-4.52 \mathrm{~cm}$ with average value of 2.64 and $2.50 \mathrm{~cm}$, implying GPS observations have larger magnitudes than the measurements of GRACE and LSDM. However, the data sets of GRACE and LSDM exhibit better consistency at most sites, as evidenced by the fact that the displacement time series of GRACE fits that of LSDM better. The main reason for the difference is that GRACE and LSDM represent smooth results limited by spatial resolution, while GPS observations are more sensitive to local effects (Wu et al., 2017). Figure 2 depicts the comparison of three data sets at sites SCXC and YNZD situated in Sichuan and Yunnan province, respectively. For the 2 sites, three data sets are highly consistent in terms of phase, and the deformations inferred from GRACE and LSDM have slightly small amplitudes in comparison with GPS observations.

In general, RMS value can reveal the scatter and magnitude of displacement time series, and therefore can be utilized to evaluate the hydrological loading effects to a certain extent. Figure 3 depicts the spatial distribution of the RMS values of GPS observations, GRACE- and LSDM-inferred displacements. The 
(a) GPS

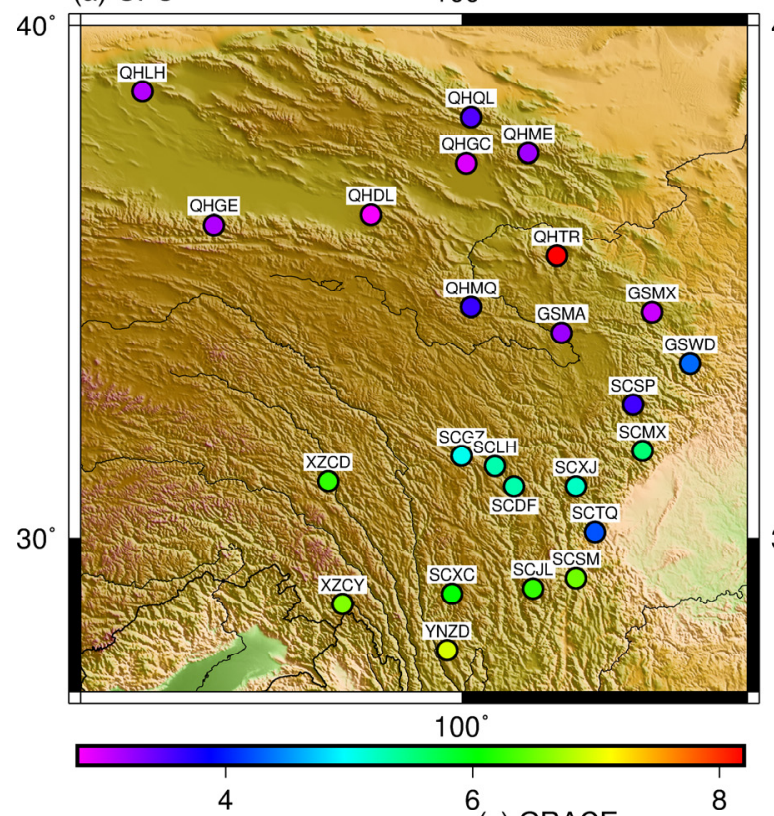

(b) LSDM

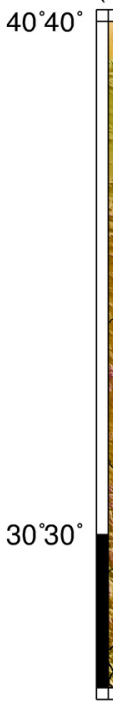

$100^{\circ}$

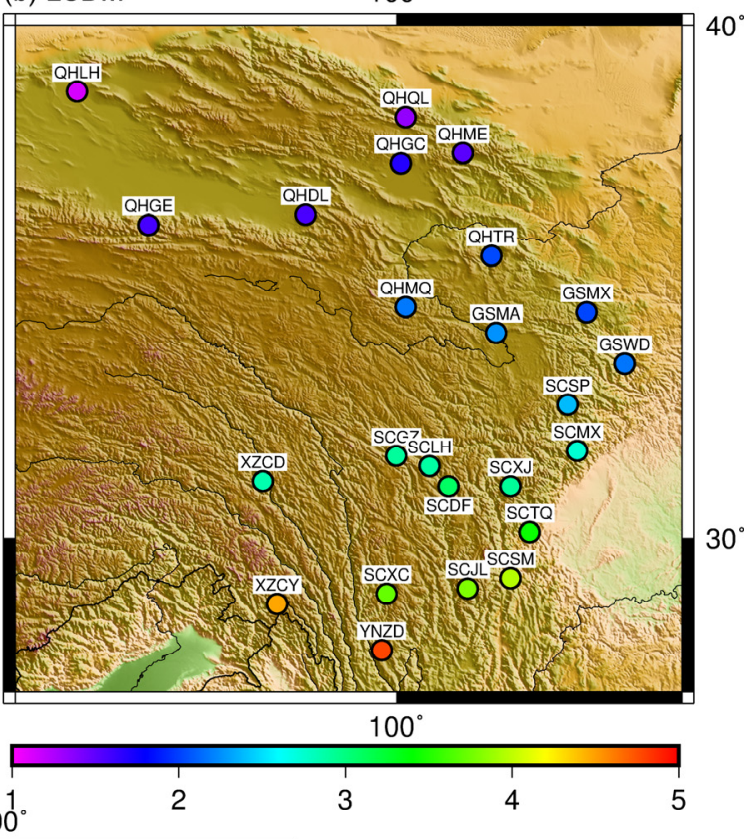

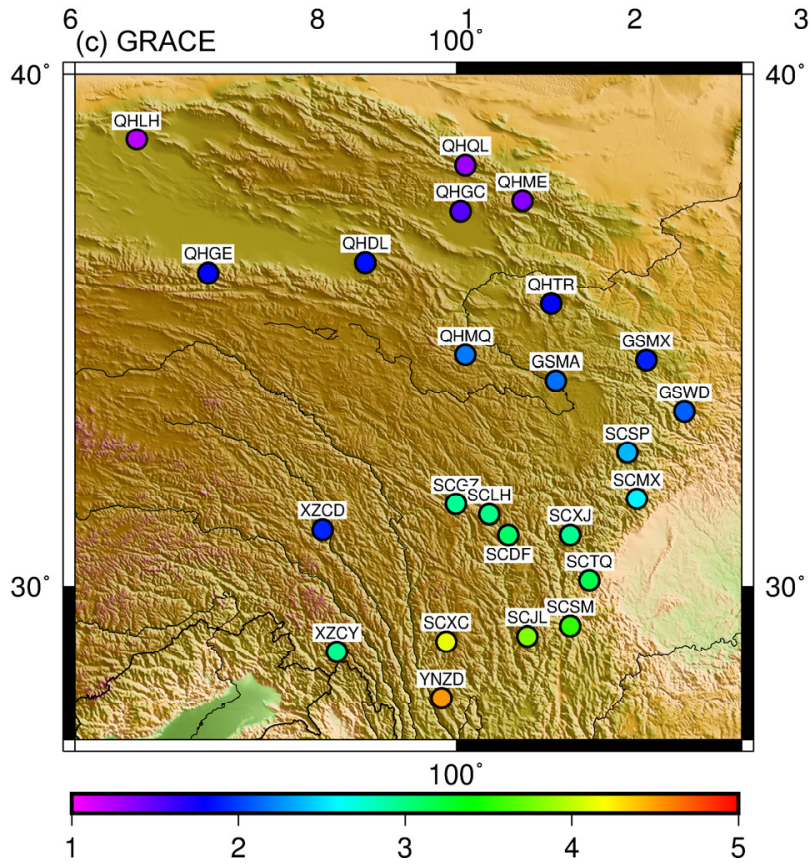

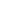
2

Fig. 3 RMS values of the hydrological loading deformations derived from GPS, GRACE, and hydrological model.

spatial distribution of the RMS values of three data sets presents strong latitude dependence, and large RMS values are concentrated on the sites located in the southern area of this region. The possible reason of this phenomenon is that these sites are situated in the region with significant water storage variations, leading to the relatively evident hydrological loading effects. Notably, the RMS value of GPS observations is abnormal at the site QHTR (up to $8.20 \mathrm{~cm}$ ), which may be associated with the data quality and errors of GPS observations. For the site QHTR, many outliers, large gap, and obvious linear trend exist in the raw position time series. Apart from this site, the largest RMS of the measurements derived from GPS, GRACE, and LSDM is observed up to 6.95, 4.52, and $4.78 \mathrm{~cm}$ at site YNCD, where dominated by high water storage variations. The RMS values of three data sets tend to occurrence a downward trend as the latitude increases, and low RMS values are cumulated at the sites located in the northern area of this region. The result illustrates that the hydrological loading effects around the eastern Tibetan Plateau exhibit strong latitude dependence, which are related to the local climate and water storage variations.

\subsection{COMPARISON OF HYDROLOGICAL LOADING DEFORMATIONS AT SEASONAL TIMESCALES}

Numerous studies claim that GPS vertical observations and hydrological loading deformations have pronounced annual cycle, and annual signals generally contain more geophysical meaning (Ray et al., 2008; Xu et al., 2016; Li et al., 2017a). Thus, the main focus is on the annual signal of three data sets in the latter analysis. Considering the influence of 


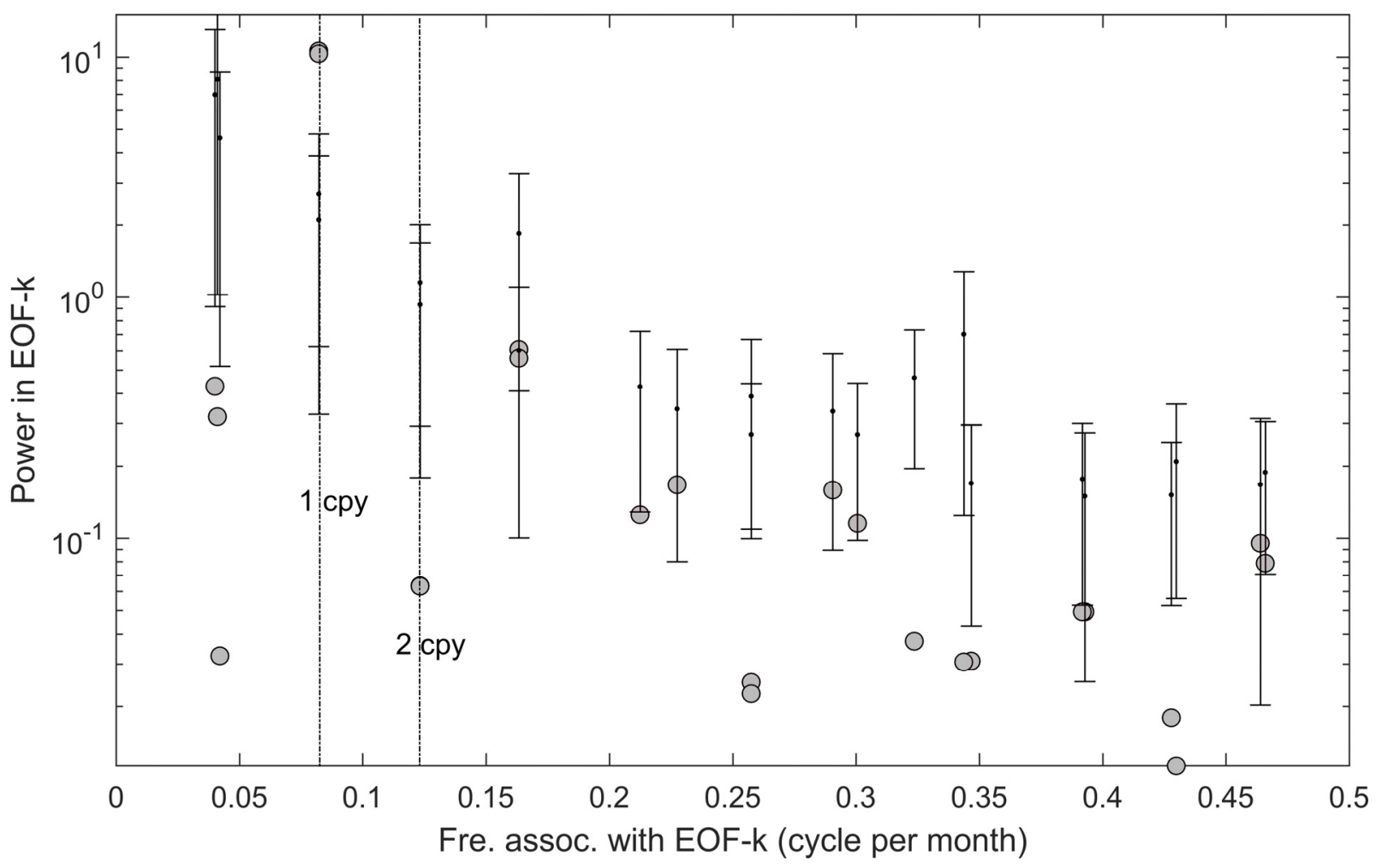

Fig. 4 Eigen spectrum of GRACE-inferred displacements for site YNZD, plotted against the dominant frequency associated with corresponding EOFs. The error bars are the $95 \%$ confidence intervals calculated from 100 realizations of surrogate data.

colored noise, appropriate statistical significance tests are necessary to distinguish the signal from noise. In this case, Monte Carlo Singular Spectrum Analysis (MCSSA) is utilized to model annual signal of three data sets, and then to make the comparison of estimated hydrological loading deformations at seasonal timescales. As summarized in Chen et al. (2013), a window size of 2-years is chosen to obtain sufficient resolution to model the annual signal. Taking the site YNZD situated in Yunnan province as an example, the annual signals of the data sets of GPS, LSDM, and GRACE are reconstructed. A normalized reduced Fourier transform (RFT) is performed for each Empirical Orthogonal Function (EOF). Figure 4 depicts the dominant frequency associated with corresponding EOFs of GRACE data sets for site YNZD (Vautard et al., 1992). The result shows that pairs $(1,2)$ meet $|\Delta f<0.75 /(2 m)|$, a selection criteria based on EOF shape, and have frequencies near the nominal seasonal frequency, implying these EOF pairs represent a stochastic seasonal component at the $95 \%$ confidence level. The EOF pairs $(1,2)$ still lie outside the error bars, implying that the signal corresponding to EOF pairs $(1,2)$ is the annual signal we expected, which is not contaminated by colored noise. Similarity, MCSSA is performed to model the annual signals of GPS and LSDM data sets, and the comparison of modeled annual signal is presented in Figure 5. The annual signals of LSDM and GRACE data sets fit that of GPS observations almost perfectly in terms of amplitude and phase, suggesting hydrological loading deformations can well explain the annual oscillations of GPS observations.
Subsequently, MCSSA is utilized to model the annual signals of three data sets for 10 selected sites in order to better characterize hydrological loading variations over this region. Among the 10 selected sites, 4 sites (i.e., QHDL, QHGC, QHGE, and QHMQ) are situated in the Qinghai province which is the high-latitude area of this region, 2 sites (i.e., GSMA and GSWD) are located in the Shanxi province which is the mid-latitude area, and the other 4 sites (i.e., SCLH, SCSM, SCXC, and SCXJ) are situated in the Sichuan province which is the lowlatitude area. Figure 6 shows the modeled annual signals of three data sets for the selected 10 sites. Clearly noticeable is the fact that the annual signals of LSDM measurements fit better with that of GPS observations than GRACE. Compared with LSDM and GRACE, GPS site is more sensitive to local mass changes, and the annual signals of GPS observations for the 10 sites exhibit different variations. The amplitudes of the annual signals of GPS observations at 2 sites GSMA and GSWD tend to decrease year by year, while the enlargement of the amplitude of annual signal occurs at site QHGE. As the latitude decreases, the amplitudes of the annual signals of three data sets become larger, especially for GPS observations. The amplitudes of annual signals at the 4 sites located in Sichuan province are relatively large in comparison with other sites. This result further confirms the conclusion of section 3.1. For the 3 sites (i.e., GSMA, GSWD, and QHGE) located in Qinghai and Shanxi provinces, the annual signals of LSDM and GRACE data sets are poor match for that of GPS observations, implying hydrological loading cannot well explain the 


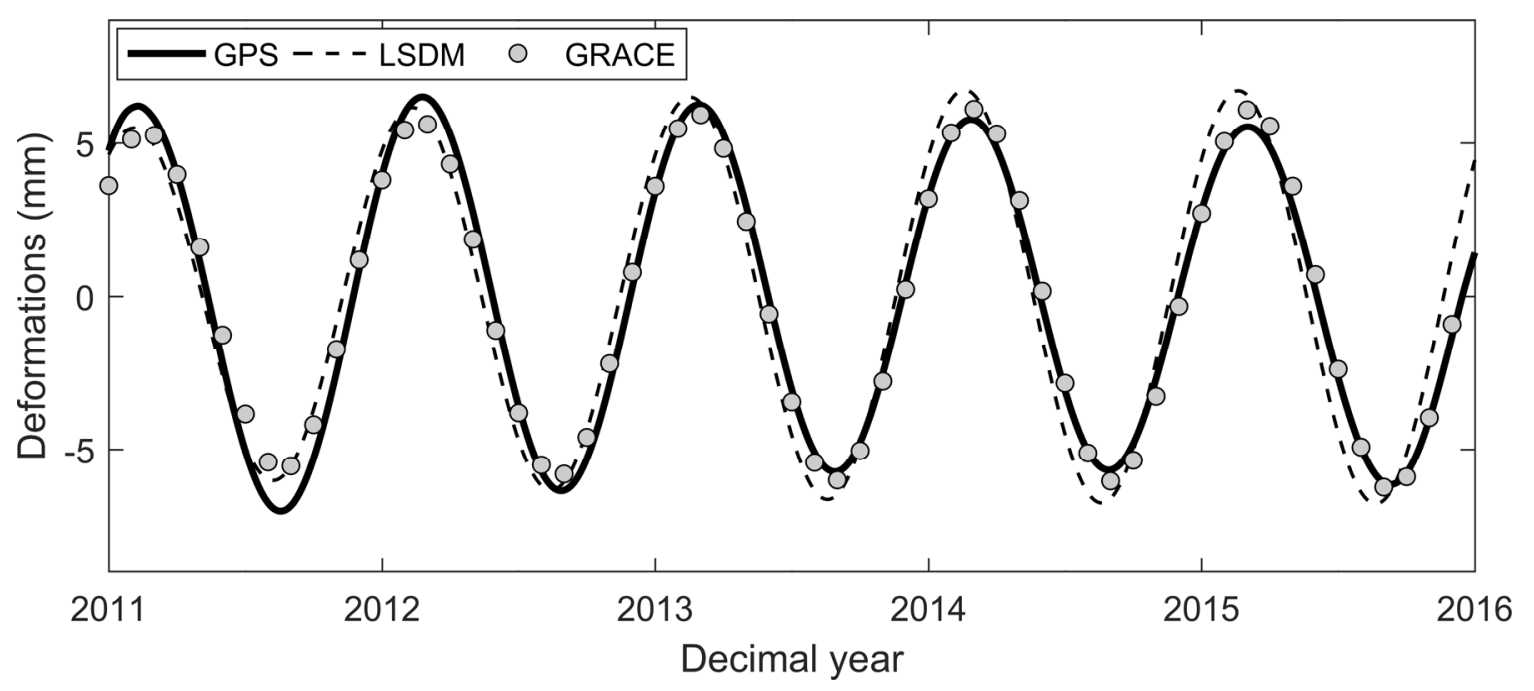

Fig. 5 Comparison of modeled annual signal of the data sets of GPS, LSDM, and GRACE at site YNZD.

annual oscillations of GPS observations. As for the 4 sites situated in Sichuan province, the annual signals of LSDM and GRACE data sets agree well with that of GPS observations, whereas the amplitudes seem slightly smaller, illustrating hydrological loading effects can partly explain the annual oscillations of GPS observations. Other factors (e.g., other geophysical effects, systematic errors, and bedrock thermal expansion) and hydrological loading jointly lead to the annual oscillations of GPS observations for the 4 sites.

\subsection{CROSS WAVELET SPECTRUM ANALYSIS}

In order to assess the consistency, the crosswavelet transform (XWT) is chosen to characterize the correlation and phase relationship between different data sets in the time-frequency space. We average GPS position time series into month samples to allow the comparison with GRACE-inferred displacements. Figure 7 shows the cross wavelet spectrum between the data sets of GPS/LSDM and GPS/GRACE at the site YNCD. The regions surrounded by thick, black contours designate the common power regions that have passed the significance test at $95 \%$ level, and the phase relationship is depicted as the arrows (with in-phase pointing right, anti-phase pointing left, GPS leading LSDM or GRACE by $90^{\circ}$ pointing straight down). In general, XWT uses the hypothesis noise model assuming a first-order autoregressive $(\mathrm{AR}(1))$ process, which may result in unreliable conclusions due to the fact that the noise in the GPS observations can generally be described as Power Law (PL) (Langbein et al., 2019; He et al., 2019). Considering the effect of hypothesis noise model, we adopted the approach proposed by $\mathrm{Xu}$ (2017) to address this problem, which extends the significance test with the generalized Gauss Markov (GGM) stochastic model as the null hypothesis. The GGM stochastic model is proposed by Langbein (2004), which includes AR(1) and PL as special cases. The spectrum for GGM has the form (Bos et al., 2014):

$$
\mathrm{P}(f)=\frac{2 \sigma^{2}}{f_{s}^{2}\left[1+\alpha^{2}-2 \alpha \cos \left(2 \pi f / f_{s}\right)\right]^{d}}
$$

where $f_{s}$ is the sampling frequency. For special cases when $d=1$, GGM converts into $\operatorname{AR}(1)$, and when $\alpha=1$, GGM is equal to standard PL. In this section, the noise model GGM $+\mathrm{WH}$ is utilized to establish null hypothesis for the significance test.

For the data sets of GPS/LSDM, the high spectral energy in common power area is concentrated on the period scale of 256-512 days corresponding to annual cycle in the whole time span (see Fig. 7). The arrows around the annual cycle almost point right, indicating the data sets of GPS/LSDM appear complete in-phase relationship. Similarity, for the data sets of GPS/GRACE, the high spectral energy in common power area is cumulated at the period scale of $\sim 1$ yr (i.e., annual cycle). The arrows around $1 \mathrm{yr}$ point right with slowly varying phase lag, suggesting that the data sets of GPS/GRACE occur significant inphase relationship. Moreover, the mean phase angle of GPS/LSDM and GPS/GRACE over the common power area are $13.07^{\circ} \pm 1.86^{\circ}$ and $25.71^{\circ} \pm 2.35^{\circ}$, and the mean semblance are 0.97 and 0.90 , implying three data sets appear evident consistency at site YNCD in the whole time span.

Then, XWT is utilized to characterize the consistency between three data sets for the other sites, and the result of mean semblance is summarized in Figure 8. For the data sets of GPS/LSDM, the poor consistency only appears at sites QHQL and QHTR, which are located in the high-latitude area of this region. As for the data sets of GPS/GRACE, the poor consistency occurs at sites QHQL, QHMQ, QHTR, SCMX, and XZCY, which are mostly situated in the mid- and high-latitude area of this region. The mean semblance of GPS/GRACE and GPS/GRACE varies from -0.56 to 0.99 and -0.89 to 0.99 with average value of 0.84 and 0.76 , respectively. Moreover, the mean semblance of GPS/GRACE above 0.9 is observed at $67 \%$ of the sites, while it reaches $79 \%$ 

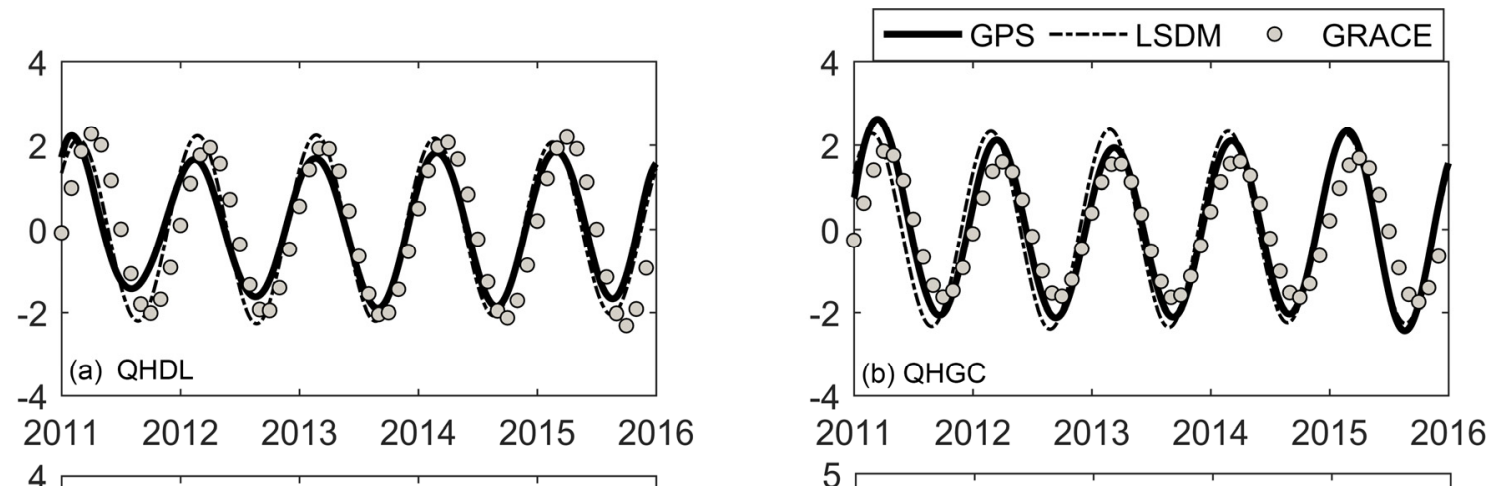

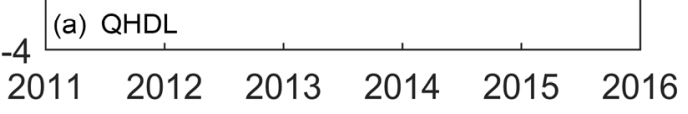
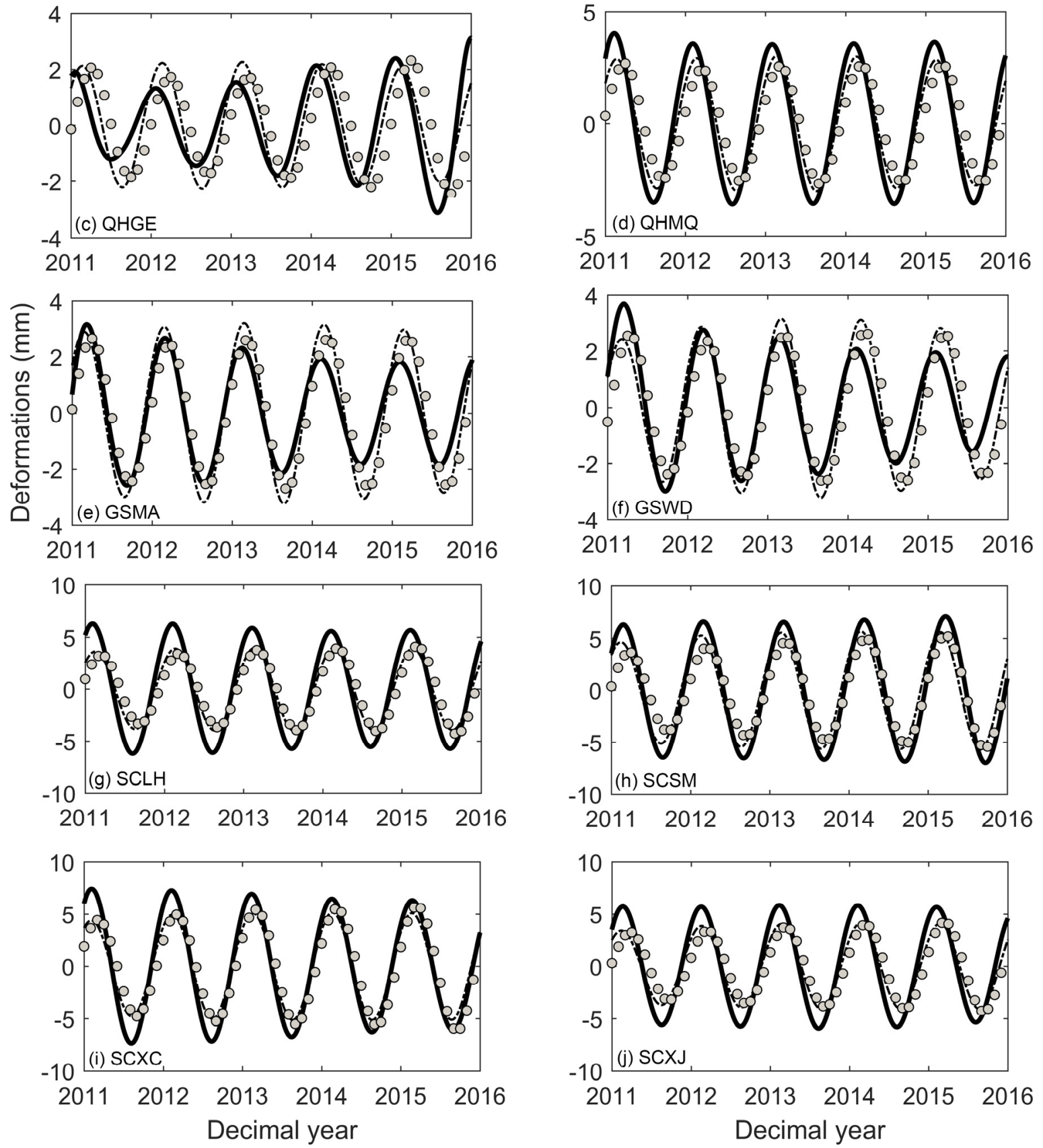

Fig. 6 Comparison of modeled annual signal of three data sets for selected 10 sites. 

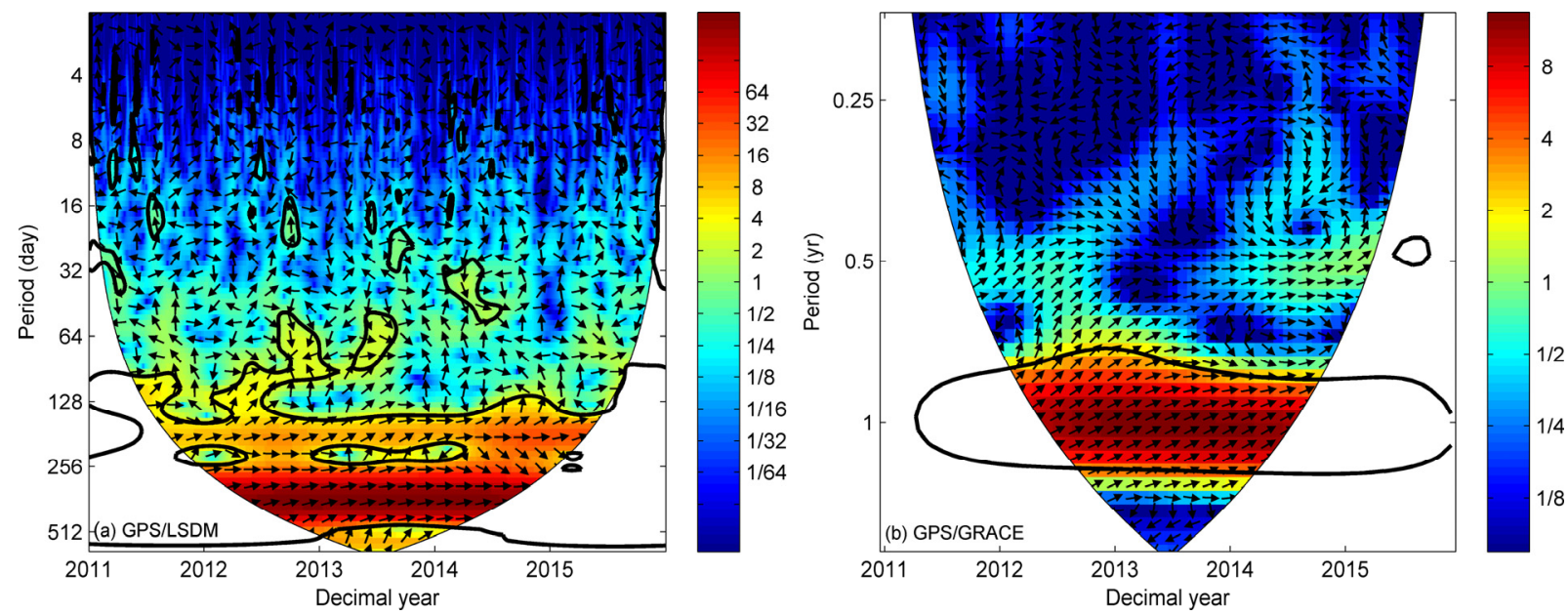

Fig. 7 Cross wavelet spectrum between the data sets of GPS/LSDM (a), GPS/GRACE (b) at site YNZD. Thin, black lines denote the Cone of Influence (COI) that delimits the region not influenced by edge effects.

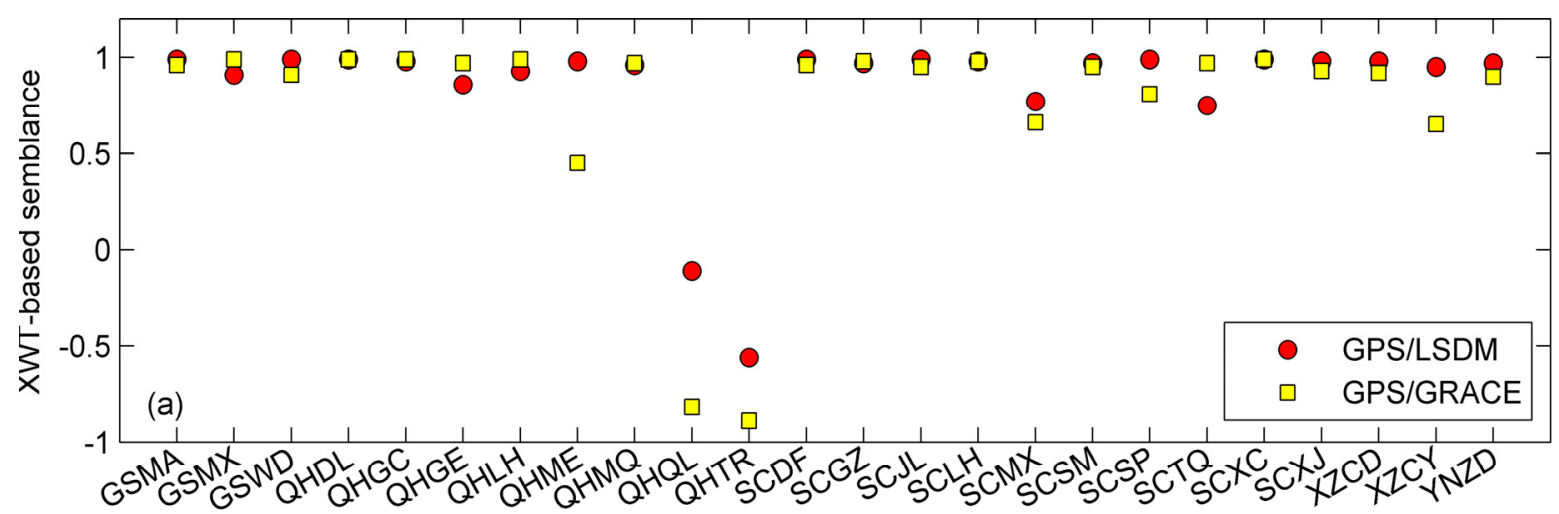

(b) GPS/LSDM

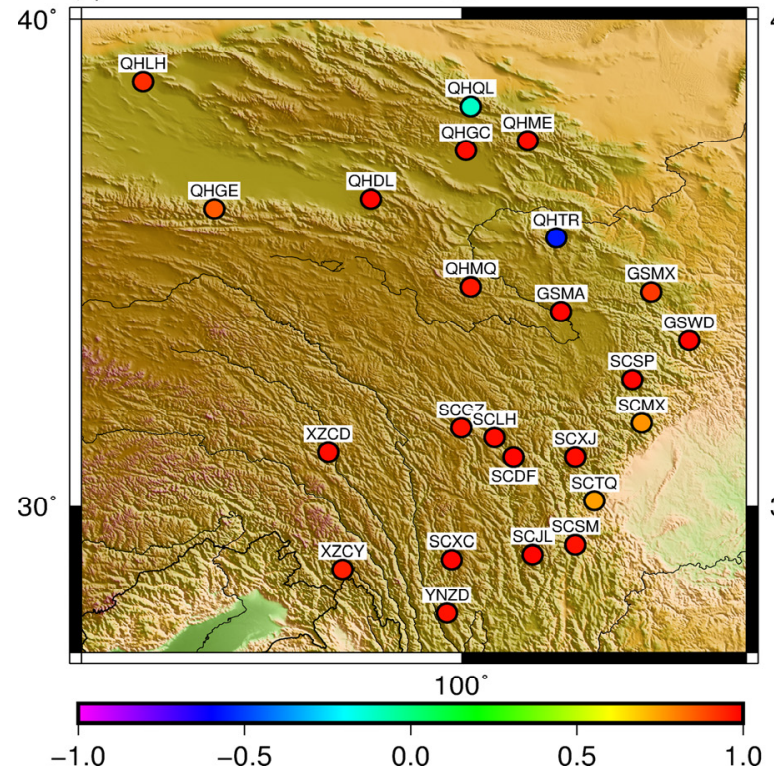

(c) GPS/GRACE

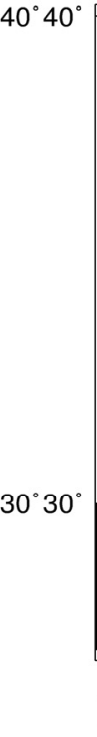

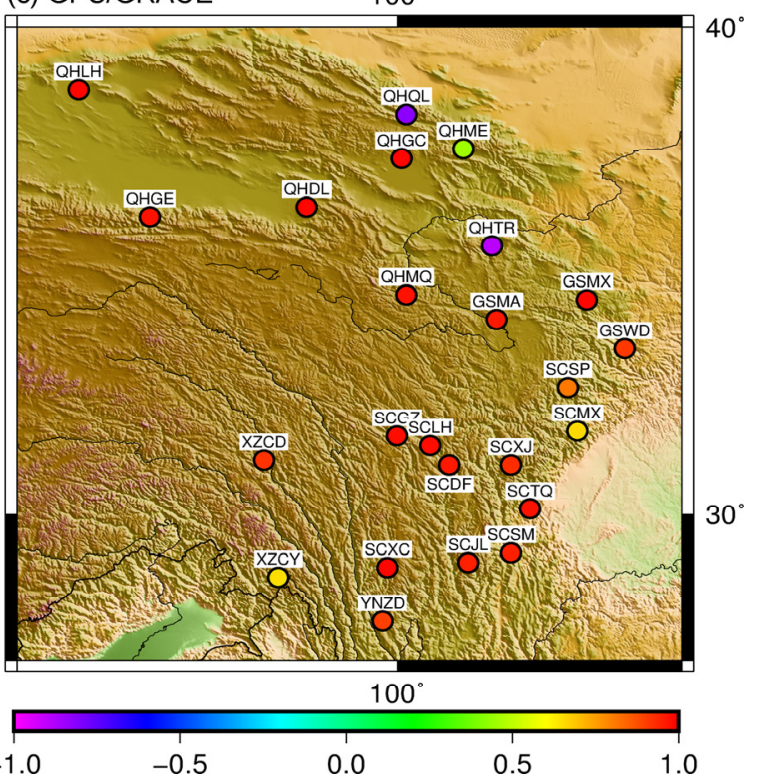

Fig. 8 The comparison (a) and spatial distribution of the mean semblance values between the data sets of GPS/LSDM (b) and GPS/GRACE (c). 
Table 1 RMS reduction of GPS observations after hydrological loading correction.

\begin{tabular}{lclclc}
\hline Site & $\begin{array}{c}\text { RMS reduction } \\
(\mathbf{c m})\end{array}$ & Site & $\begin{array}{c}\text { RMS reduction } \\
(\mathbf{c m})\end{array}$ & Site & $\begin{array}{c}\text { RMS reduction } \\
(\mathbf{c m})\end{array}$ \\
\hline GSMA & 0.29 & QHMQ & 0.94 & SCSM & 1.55 \\
GSMX & -0.13 & QHQL & -0.39 & SCSP & 0.21 \\
GSWD & 0.36 & QHTR & -0.59 & SCTQ & -0.27 \\
QHDL & 0.24 & SCDF & 1.33 & SCXC & 2.02 \\
QHGC & 0.42 & SCGZ & 1.24 & SCXJ & 1.40 \\
QHGE & 0.23 & SCJL & 1.45 & XZCY & 0.98 \\
QHLH & -0.009 & SCLH & 1.68 & XZCD & 1.44 \\
QHME & 0.18 & SCMX & 0.43 & YNZD & 1.39 \\
\hline
\end{tabular}

for GPS/LSDM. The results suggest that the data sets of GPS/LSDM display better consistency than GPS/GRACE, and LSDM can well model the hydrological loading deformations around the eastern Tibetan.

\subsection{EFFECTS OF HYDROLOGICAL LOADING ON GPS OBSERVATIONS}

As summarized in section 3.3, the Land Surface Discharge Model (LSDM) can model the crustal deformations induced by hydrological loading better than GRACE. Therefore, the hydrological loading deformations inferred from LSDM are used to remove the effects of hydrological loading from GPS observations. The effects of hydrological loading can be assessed from the variations of RMS values, velocity uncertainties, and noise properties. Table 1 shows the RMS reduction of GPS observations after removing the LSDM-inferred displacements. Similarity, the spatial distribution of RMS reductions exhibits strong latitude dependence, the RMS values of GPS observations at the sites situated in the lowlatitude area of the eastern Tibetan Plateau have reduced significantly. The largest RMS reduction occurs at the site SCXC, reaching $2.02 \mathrm{~cm}$. The poor improvement of RMS values mostly appears at the sites situated in the mid- and high-latitude area of the eastern Tibetan Plateau. For the sites situated in the mid- and high-latitude area, RMS reductions of GPS observations range from -0.59 to $0.94 \mathrm{~cm}$ with average value of $0.14 \mathrm{~cm}$, while RMS reductions range from -0.27 to $2.02 \mathrm{~cm}$ with average value of $1.14 \mathrm{~cm}$ in the low-latitude area. As summarized in section 3.2, hydrological loading cannot well explain the seasonal oscillations of most GPS observations in the mid- and high-latitude area. Thus, the hydrological loading correction cannot significantly improve the precision of most GPS observations in this area.

Subsequently, the CATS software developed by Williams et al. (2008) is utilized to characterize the effects of hydrological loading on the noise properties and velocity uncertainties. Numerous studies indicate that a combination of White Noise (WN) and Flicker Noise (FN) is suitable for describing the noise properties of most GPS position time series. In this case, we confine our attentions to $\mathrm{WN}$ and $\mathrm{FN}$, although other more complex noise (e. g., first-order Gauss Markov (GM) noise and Band Pass filtered (BP) noise) may exist in GPS observations. Figure 9 summarizes the variations of noise properties and velocity uncertainties after removing the hydrological loading effects. For most sites, the magnitude of FN is decreased with different amplitudes, while the magnitude of WN is increased. This indicates that hydrological loading effects have altered the noise properties of the GPS observations of most sites. Meanwhile, the reduction of velocity uncertainties appears at 21 sites, and the poor improvement only occurs at 3 sites. The reduction of velocity uncertainties ranges from -0.15 to $0.35 \mathrm{~mm} / \mathrm{yr}$, and it reaches $0.35 \mathrm{~mm} / \mathrm{yr}$ at site SCSM. The results suggest that applying hydrological loading correction can suppress the colored noise of most GPS observations, and then improve the precision of velocity estimation for almost all sites.

\section{CONCLUSION}

In this study, the data sets of GPS, LSDM, and GRACE at 24 sites are collected to characterize the hydrological loading effects over the eastern Tibetan Plateau. Firstly, RMS scatter of three data sets is utilized to measure the hydrological loading effects over this region. The spatial distribution of the RMS values of three data sets presents strong latitude dependence, and large RMS values are concentrated on the sites located in the southern area of this region. The possible reason of this phenomenon is that these sites are situated in the region with significant water storage variations, leading to the relatively evident hydrological loading effects. Then, we make a comparison of hydrological loading deformations at seasonal timescales. Considering that colored noise can be mistaken as annual signal, MCSSA is utilized to model the annual signals of three data sets for 10 selected sites in order to better characterize hydrological loading variations. Similarity, the amplitudes of annual signals in the southern area of this region are relatively large. After that, XWT is performed to assess the consistency between different data sets, and the noise model GGM $+\mathrm{WH}$ is utilized to establish null hypothesis for the significance test. The mean semblance of GPS/GRACE and GPS/GRACE varies from -0.56 to 0.99 and -0.89 to 0.99 with average value of 0.84 and 0.76 , respectively. Moreover, the mean semblance of GPS/GRACE above 0.9 is observed at $67 \%$ of the sites, while it reaches $79 \%$ for GPS/LSDM. The results suggest that the data sets of GPS/LSDM present better consistency than GPS/GRACE. Finally, we investigate the effects of hydrological loading on GPS observations. The 


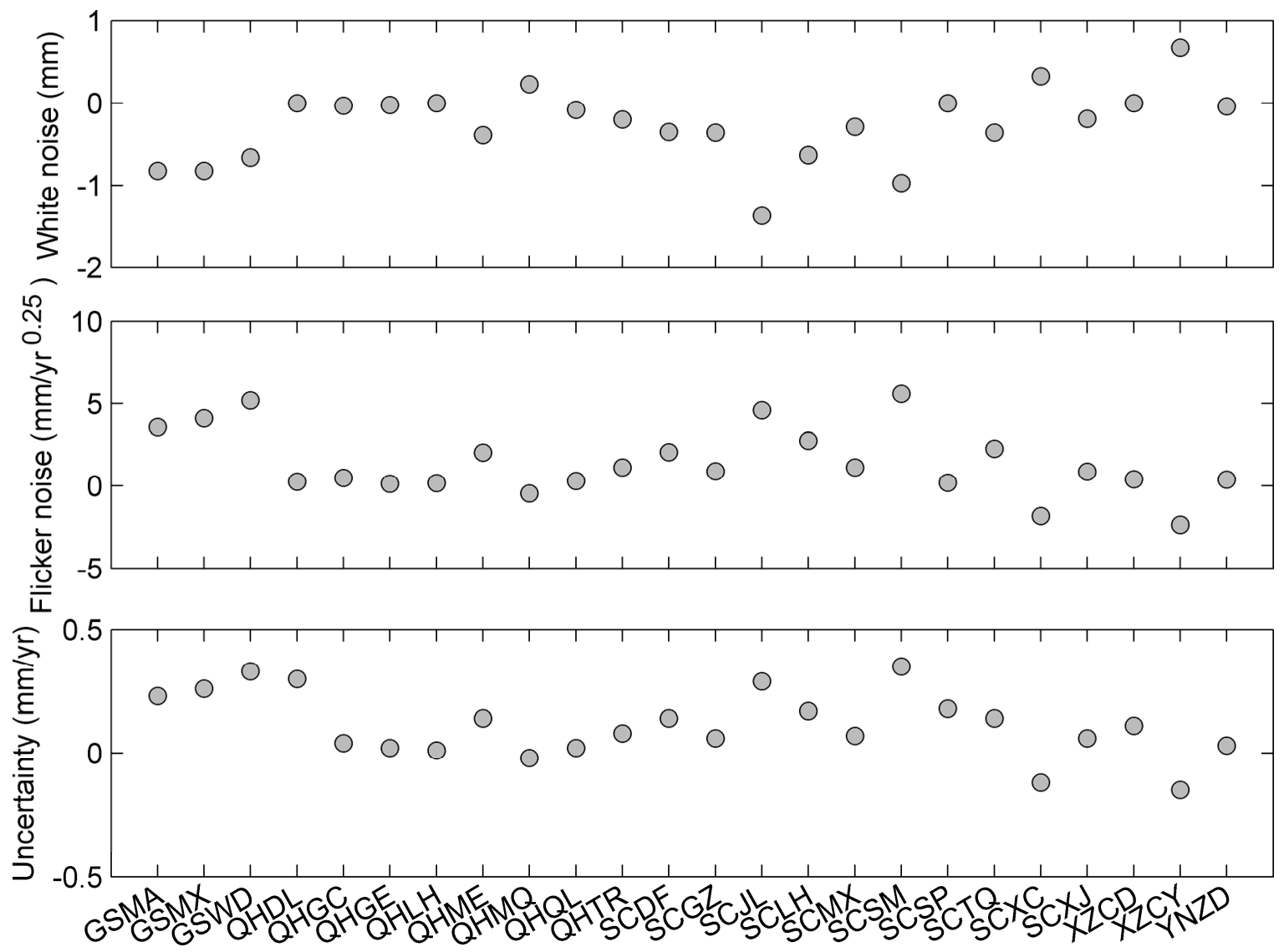

Fig. 9 The difference (i.e., original minus corrected) of white noise magnitude, flicker noise magnitude, and velocity uncertainty after removing the hydrological loading deformations.

noise properties of most GPS observations have changed after removing hydrological loading deformations. Meanwhile, the velocity uncertainties are reduced at 23 sites, and the range of reduction is $0.15-0.35 \mathrm{~mm} / \mathrm{yr}$. Thus, applying hydrological loading correction can effectively improve the precision of velocity estimation for almost all sites. On the basis of this study, we will try to explore the tectonic movements around the eastern Tibetan Plateau in our future work.

\section{ACKNOWLEDGEMENT}

We are very grateful to China Earthquake Administration (CEA) for providing GPS position time series, and GeoForschungs Zentrum (GFZ) for providing the hydrological loading deformations estimated by the Global Land Surface Discharge Model (LSDM). This study is support by the Fundamental Research Funds for the Central Universities (2019B60614), Postgraduate Research \& Practice Innovation Program of Jiangsu Province (SJKY19_0514), a fundation of Natural Science Foundation of Chongqing (cstc2019jcyj-msxmX0701) and National Key R\&D Program of China (No. 2018YFC1508603).

\section{REFERENCES}

Allen, M.R. and Smith, L.A.: 1996, Monte Carlo SSA: detecting irregular oscillations in the presence of colored noise. J. Clim., 9, 12, 3373-3404.

DOI: $10.1175 / 1520-0442(1996) 009$
Bevis, M., Alsdorf, D., Kendrick, E. et al.: 2005, Seasonal fluctuations in the mass of the Amazon River system and Earth's elastic response. Geophys. Res. Lett., 32, 16, L16308. DOI: 10.1029/2005GL023491

Bos, M.S., Williams, S.D.P., Araújo, I.B. and Bastos, L.: 2014, The effect of temporal correlated noise on the sea level rate and acceleration uncertainty. Geophys. J. Int., 196, 3, 1423-1430. DOI: 10.1093/gji/ggt481

Chanard, K., Avouac, J.P., Ramillien, G., et al.: 2014, Modeling deformation induced by seasonal variations of continental water in the Himalaya region: sensitivity to Earth elastic structure. J. Geophys. Res., Solid Earth, 119, 6, 5097-5113. DOI: $10.1002 / 2013 J B 010451$

Chen, Q., Dam, T.V., Sneeuw, N., Collilieux, X., Weigelt, M. and Rebischung, P.: 2013, Singular spectrum analysis for modeling seasonal signals from GPS time series. J. Geodyn., 72, 12, 25-35.

DOI: 10.1016/j.jog.2013.05.005

Dill, R. and Dobslaw, H.: 2013, Numerical simulations of global-scale high-resolution hydrological crustal deformations. J. Geophys. Res., Solid Earth, 118, 9, 5008-5017. DOI: 10.1002/jgrb.50353

Fan, W. and Shearer, P.M.: 2015, Detailed rupture imaging of the 25 April 2015 Nepal earthquake using teleseismic P waves. Geophys. Res. Lett., 42, 14, 5744-5752. DOI: 10.1002/2015GL064587

Farrell, W.E.: 1972, Deformation of the Earth by surface loads. Rev. Geophys., 10, 3, 751-797.

Fritsche, M., Doll, P. and Dietrich, R.: 2012, Global-scale validation of model-based load deformation of the Earth's crust from continental watermass and atmospheric pressure variations using GPS. J. 
Geodyn., 59-60, 133-142.

DOI: $10.1016 /$ j.jog.2011.04.001

Fu, Y. and Freymueller, J.T.: 2012, Seasonal and long-term vertical deformation in the Nepal Himalaya constrained by GPS and GRACE measurements. J. Geophys. Res., Solid Earth, 117, B03407. DOI: 10.1029/2011JB008925

Grinsted, A., Moore, J.C. and Jevrejeva, S.: 2004, Application of the cross wavelet transform and wavelet coherence to geophysical time series. Nonlin. Process. Geophys., 11, 5/6, 561-566. DOI: 10.5194/npg-11-561-2004

He, M., Shen, W., Pan, Y., Chen, R., Ding, H. and Guo, G.: 2017, Temporal-spatial surface seasonal mass changes and vertical crustal deformation in south China block from GPS and GRACE measurements. Sensors, 18, 1, 99. DOI: 10.3390/s18010099

He, X., Bos, M.S., Montillet, J.P. and Fernandes, R.M.S.: 2019, Investigation of the noise properties at low frequencies in long GNSS time series. J. Geod. DOI: $10.1007 / \mathrm{s} 00190-019-01244-y$

King, M., Moore, P., Clarke, P. et al.: 2006, Choice of optimal averaging radii for temporal GRACE gravity solutions, a comparison with GPS and satellite altimetry. Geophys. J. Int., 166, 1, 1-11. DOI: $10.1111 / \mathrm{j} .1365-246 X .2006 .03017 . x$

Kusche, J. and Schrama, E.J.O.: 2005, Surface mass redistribution inversion from global GPS deformation and Gravity Recovery and Climate Experiment (GRACE) gravity data. J. Geophys. Res., 110, B09409. DOI: 10.1029/2004JB003556

Langbein, J.: 2004, Noise in two-color electronic distance meter measurements revisited. J. Geophys. Res., Solid Earth, 109, B04406. Langbein, J.: 2004, Noise in twocolor electronic distance meter measurements revisited. J. Geophys. Res., Solid Earth, 109, B04406. DOI: 10.1029/2003JB002819

Langbein, J. and Svarc, J.L.: 2019. Evaluation of temporally correlated noise in Global Navigation Satellite System time series: Geodetic monument performance. J. Geophys. Res., Solid Earth, 124, 1, 925-942. DOI: $10.1029 / 2018 J B 016783$

Liu, R., Li, J., Fok, H.S., Shum, C.K. and Li, Z.: 2014, Earth surface deformation in the North China Plain detected by joint analysis of Grace and GPS data. Sensors, 14, 10, 19861-19876. DOI: 10.3390/s141019861

Li, S., Shen, W., Pan, Y. and Zhang, T.: 2019, Surface seasonal mass changes and vertical crustal deformation in North China from GPS and GRACE measurements. Geodesy and Geodynamics. DOI: 10.1016/j.geog.2019.05.002

Li, Z., Yue, J.P., Li, W., Lu, D.K. and Li, X.: 2017a, A comparison of hydrological deformation using GPS and global hydrological model for the Eurasian plate. Adv. Space Res., 60, 3, 587-596. DOI: 10.1016/j.asr.2017.04.023

Li, Z., Yue, J.P., Li, W. and Lu, D.K.: 2017b, Investigating mass loading contributes of annual GPS observations for the Eurasian plate. J. Geodyn., 111, 43-49. DOI: $10.1016 /$ j.jog.2017.07.001

Moreira, D. M., Calmant, S., Perosanz, F., Xavier, L., Rotunno Filho, O.C., Seyler, F. et al.: 2016, Comparisons of observed and modeled elastic responses to hydrological loading in the Amazon Basin. Geophys. Res. Lett., 43, 18, 9604-9610. DOI: 10.1002/2016GL070265

Nahmani, S.: 2012, Hydrological deformation induced by the West African Monsoon: Comparison of GPS,
GRACE and loading models. J. Geophys. Res., Solid Earth, 117, B05409. DOI: 10.1029/2011JB009102

Pan, Y., Shen, W., Shum, C.K. and Chen, R.: 2019, Spatially varying surface seasonal oscillations and 3-D crustal deformation of the Tibetan Plateau derived from GPS and GRACE data. Earth Planet. Sc. Lett., 502, 15, 12-22. DOI: 10.1016/j.eps1.2018.08.037

Ray, J., Altamimi, Z., Collilieux, X. and van Dam, T.: 2008, Anomalous harmonics in the spectra of GPS position estimates. GPS Solut., 12, 1, 55-64. DOI: 10.1007/s10291-007-0067-7

Ray, J., Griffiths, J., Collilieux, X. and Rebischung, P.: 2013, Sub-seasonal GNSS positioning errors. Geophys. Res. Lett., 40, 5854-5860. DOI: $10.1002 / 2013$ GL058160

Su, X., Wang, Z., Meng, G. and Xu, W.: 2015, Pre-seismic strain accumulation and co-seismic deformation of the 2015 Nepal Ms 8.1 earthquake observed by GNSS. Chin. Sci. Bull., 60, 22, 2115-2123, (in Chinese).

Swenson, S., Chambers, D. and Wahr, J.: 2008, Estimating geocenter variations from a combination of GRACE and ocean model output. J. Geophys. Res., Solid Earth, 113, B08410. DOI: 10.1029/2007JB005338

van Dam, T., Wahr, J. and Lavalle'e, D.: 2007, A comparison of annual vertical crustal displacements from GPS and Gravity Recovery and Climate Experiment (GRACE) over Europe. J. Geophys. Res., Solid Earth, 112, B03404. DOI: 10.1029/2006JB004335

Vautard, R., Yiou, P. and Ghil, M.: 1992, Singular-spectrum analysis: A toolkit for short, noisy chaotic signals. Physica D: Nonlinear Phenom, 58, 1-4, 95-126. DOI: 10.1016/0167-2789(92)90103-T

Williams, S.D.: 2008, CATS: GPS coordinate time series analysis software. GPS Solut., 12, 2, 147-153. DOI: 10.1007/s10291-007-0086-4

Wu, Y., Zhao, Q., Zhang, B. and Wu, W.: 2017, Characterizing the seasonal crustal motion in Tianshan area using GPS, GRACE and surface loading models. Remote Sens., 9, 12, 1303. DOI: 10.3390/rs9121303

$\mathrm{Xu}, \mathrm{C} .:$ 2016, Investigating mass loading contributors of seasonal oscillations in GPS observations using wavelet analysis. Pure Appl. Geophys., 173, 8, 27672775. DOI: $10.1007 / \mathrm{s} 00024-016-1301-4$

Xiang, Y., Yue, J.P., Tang, K., Li, Z. et al.: 2018, Joint analysis of seasonal oscillations derived from GPS observations and hydrological loading for mainland China. Adv. Space Res., 62, 11, 3148-3161. DOI: $10.1016 /$ j.asr.2018.08.028

$\mathrm{Xu}, \mathrm{C} .:$ 2017, Detecting periodic oscillations in astronomy data: revisiting wavelet analysis with coloured and white noise. Mon. Not. R. Astron. Soc., 466, 4, $3827-$ 3833. DOI: $10.1093 / \mathrm{mnras} / \mathrm{stw} 3349$

Yagi, Y. and Okuwaki, R.: 2015, Integrated seismic source model of the 2015 Gorkha, Nepal, earthquake. Geophys. Res. Lett., 42, 15, 6229-6235. DOI: 10.1002/2015GL064995

Zhang, T., Shen, W., Pan, Y. and Luan, W.: 2018, Study of seasonal and long-term vertical deformation in Nepal based on GPS and GRACE observations. Adv. Space Res., 61, 4, 1005-1016. DOI: 10.1016/j.asr.2017.10.049

Zou, R., Wang, Q., T. Freymueller, J. et al.: 2015, Seasonal hydrological loading in southern Tibet detected by joint analysis of GPS and GRACE. Sensors, 15, 12, 30525-30538. DOI: 10.3390/s151229815 